\title{
Research on Tool Wear Factors for Milling Wood-plastic Composites Based on Response Surface Methodology
}

\begin{abstract}
Weihua Wei, ${ }^{\mathrm{a}, *}$ Yingli Li, ${ }^{\mathrm{a}}$ Yuantong Li, ${ }^{\mathrm{a}}$ Yiqi $\mathrm{Xu},{ }^{\mathrm{a}}$ and Changyong Yang ${ }^{\mathrm{b}}$
A high-speed milling experiment on wood-plastic composites was performed using cemented carbide tools, and the resulting wear pattern was studied. The influence of the cutting parameters, the cutting speed, feed speed, and axial cutting depth on the tool wear was studied via response surface methodology, and the influence of the interaction of the cutting parameters on tool wear was analyzed. Three-dimensional surface graphs and contour plots of the tool wear results were established. According to the experimental results, a mathematical model of the tool wear based on the second-order response surface methodology was established, and the model was utilized to verify its feasibility. The results show that the nose width (NW) increases with the increase of the cutting speed and axial cutting depth and decreases with the increase of feed speed. Among the factors affecting tool wear, the cutting speed had the greatest influence, followed by the feed rate, with the axial cutting depth affecting tool wear the least. According to the results of the interaction between the tool wear and the cutting parameters, a low feed speed and small axial cutting depth can be selected to ensure long tool life; for lowspeed cutting, a high feed speed and large axial cutting depth can be adopted to ensure tool life while improving machining efficiency.
\end{abstract}

Keywords: Wood-plastic composites; High-speed milling; Tool wear; Mathematical model; Response surface methodology

Contact information: a: College of Mechanical and Electrical Engineering, Nanjing Forestry University, Nanjing, 210037 China; b: Jiangsu Key Laboratory of Precision and Micro-Manufacturing Technology, Nanjing University of Aeronautics and Astronautics, Nanjing, 210016 China;

* Corresponding author: whwei@njfu.edu.cn

\section{INTRODUCTION}

Wood-plastic composites (WPCs) have the advantages that wood or plastic alone does not have, and they are widely used in automotive interiors, garden landscapes, interior design, as well as other industries. However, due to the anisotropy and non-uniformity of WPCs, during the WPCs milling process, the cutting tools are subjected to friction, vibration, impact, etc.; the tool is rapidly worn; and the tool failure evolution mechanism is complex. Therefore, the tool is required to have not only high hardness and wear resistance, but also sufficient strength and toughness (Wei et al. 2018, 2019). The use of high-performance tool materials can effectively reduce overall tool wear and extend the tool life (Darmawan et al. 2001), but the expensive tool price reduces the processing economy. As important parameters for the cutting conditions, the processing parameters have a major effect on tool wear. Selecting the appropriate machining parameters is one of the keys to improving tool life and reducing production costs (Wang et al. 2011). Ubeyli et al. (2008) investigated the effect of the feed rate on tool wearing when milling $\mathrm{B}_{4} \mathrm{C}_{\mathrm{p}}$ reinforced aluminum metal matrix composites produced via a liquid phase sintering 
method and used an optical microscope to measure the magnitude of flank wear on the tools. Experimental results indicated that a higher feed rate led to lower tool wear for the tools and that coated tools exhibited better performance than uncoated tools, with respect to the flank wear. Altan et al. (2018) used the Taguchi method and the analysis of variance (ANOVA) statistical method to study the effect of the cutting parameters on tool wear. The study indicated that the feed rate had the most significant effect on tool wear during the initial wear and rapid wear stages. In the stable wear stage, the feed rate and cutting speed had almost the same effect on tool wear, but the effect of the cutting speed was slightly greater. Szwajka and Trzepiecińsk (2016) investigated the effect of the cutting speed on tool life using a single factor method. The results showed that as the cutting speed increased, the tool life decreased. Zhu et al. (2017) pointed out that when milling highdensity fiberboard (HDF) with a TiC-reinforced $\mathrm{Al}_{2} \mathrm{O}_{3}$ ceramic cutting tool, a high spindle rotation speed and feed rate during high-speed milling lead to a high materials removal rate and a high frequency of contact between the tool and workpiece in comparison to a low speed milling, which further induced serious tool wear. In addition, the main wear forms of a TiC-reinforced $\mathrm{Al}_{2} \mathrm{O}_{3}$ ceramic cutting tool were pull-out of grain, flaking, and chipping, and the wear mechanisms were primarily abrasive wear and adhesive wear. Guo et al. (2018) found that both the $\mathrm{Si}_{3} \mathrm{~N}_{4}$ cutting tool and the $\mathrm{Al}_{2} \mathrm{O}_{3}$ cutting tool caused adhesive wear while cutting plywood, and the tool adhesive wear during high-speed cutting was more serious than during low-speed cutting. Yi et al. (2015) established a surface roughness model of a micro milling process via the response surface methodology (RSM); the model had high reliability and practicability under the experimental conditions. It could be used to select the appropriate cutting parameters and predict the surface roughness before machining. However, most of these studies were based on metal and wood materials and do not research tool wear during the high-speed milling of WPCs. In these studies, a single factor method is often used in the experimental design, no overall mathematical model is established, and the systematic analysis of interactions between the influential factors is lacking. The response surface methodology is an optimization method of comprehensive test designs and mathematical modeling, which can study the interaction between two or more factors (Chan et al. 2019). Compared with a single-factor test, RSM can comprehensively analyze the selected experiment parameters in a shorter time and in a more economical way and with fewer experiment iterations (Khuri and Mukhopadhyay 2010).

In this paper, the self-developed WPCs were used as the test object, and the highspeed milling test of WPCs was performed with a cemented carbide tool. The influence of cutting parameters and their interaction on tool wear were studied via the RSM. A mathematical model of tool wear was established, and the relationship between the cutting parameters and tool wear was obtained. The feasibility of the model was verified via ANOVA, and the optimal combination of the cutting parameters for improving tool life was determined, which provides a theoretical basis for the subsequent selection of processing parameters.

\section{EXPERIMENTAL}

\section{Materials}

The sample used in the test is a composite material made up of wood flour, polyethylene and adhesive, which was produced by Nanjing Dayuan Plastic Wood New 
Material Co. Ltd. (Nanjing, China). This wood plastic composite has good water resistance and resistance to degradation when wet. The sample size was $322 \mathrm{~mm}(\mathrm{~L}) \times 80 \mathrm{~mm}(\mathrm{~W}) \times$ $40 \mathrm{~mm}(\mathrm{H})$, and their properties are shown in Table 1.

Table 1. Properties of the WPCs

\begin{tabular}{|c|c|c|c|}
\hline $\begin{array}{c}\text { Proportion } \\
\text { (mass) }\end{array}$ & $\begin{array}{c}\text { Density } \\
\left(\mathrm{g} / \mathrm{cm}^{3}\right)\end{array}$ & $\begin{array}{c}\text { Flexural Modulus } \\
(\mathrm{MPa})\end{array}$ & $\begin{array}{c}\text { Shore Hardness } \\
(\mathrm{HD})\end{array}$ \\
\hline $\begin{array}{c}\text { Wood flour: } 65 \% \\
\text { Polyethylene: } 25 \% \\
\text { Adhesive: } 10 \%\end{array}$ & 1.19 & 28 & 58 \\
\hline
\end{tabular}

The experiment was performed with up-milling using a UCP 800 Duro CNC machining center by Mikron (Agno, Switzerland). The cemented carbide blades produced by Zhuzhou Diamond Cutting Tool Co. Ltd. (Zhuzhou, China) were used to perform the test, and the blades specifications are shown in Table 2. Before the test, the blades were installed on the arbor (model EMP01-020-G20-AP11-02, Zhuzhou Diamond Cutting co. Ltd.), which had a diameter $(D)$ of $20 \mathrm{~mm}$, and only one blade was mounted on the arbor for each set of tests.

Table 2. Specification Parameters of the Blade

\begin{tabular}{|c|c|c|c|c|c|}
\hline Model & Material & $\begin{array}{c}\text { Size: } \mathrm{L} \times \mathrm{I} . \mathrm{W} \times \mathrm{S} \\
(\mathrm{mm})\end{array}$ & $\begin{array}{c}\text { Rake Angle } \\
\gamma_{0}\left({ }^{\circ}\right)\end{array}$ & $\begin{array}{c}\text { Clearance Angle } \\
\alpha_{0}\left({ }^{\circ}\right)\end{array}$ & $\begin{array}{c}\text { Corner Radius } \\
R(\mathrm{~mm})\end{array}$ \\
\hline YD201 & $\begin{array}{c}\text { Cemented } \\
\text { Carbide }\end{array}$ & $\begin{array}{c}12.24 \times 6.5 \times \\
3.6\end{array}$ & 19 & 11 & 0.4 \\
\hline
\end{tabular}

\section{Methods}

In this test, the tool nose width (NW) was selected as the representative value of tool wear, as shown in Fig. 1. At the end of each test, the NW was measured with a Nikon DS-U3 DS digital microscopic imaging system (Tokyo, Japan).

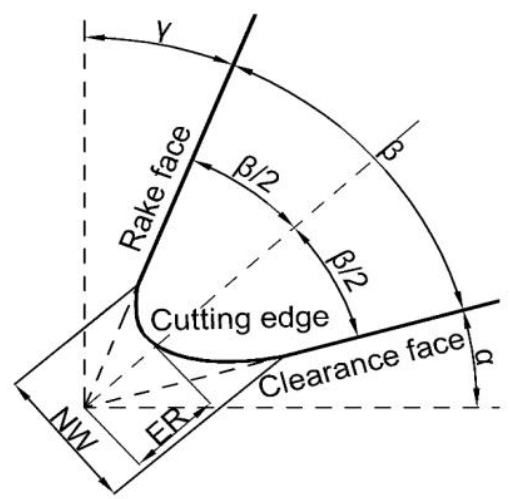

Fig. 1. Microscopic angle and geometric parameters of the cutting tool

A central composite design (CCD) for the RSM was adopted in this test. The cutting speed $(v)$, feed rate $(f)$, and axial cutting depth $\left(a_{\mathrm{p}}\right)$ were selected as the three factors, and three levels were selected as the number of levels. This design requires 20 sets of tests, including 1 set of factor designs, 6 sets of center point designs, and 1 set of axial point 
designs. During the machining test, the radial cutting depth remained unchanged $(5 \mathrm{~mm})$, and the milling length of each set was $21.12 \mathrm{~m}$. The cutting parameters and their levels are shown in Table 3.

Table 3. Cutting Parameters and Levels

\begin{tabular}{|c|c|c|c|}
\hline \multirow{2}{*}{ Cutting Parameters } & \multicolumn{3}{|c|}{ Levels } \\
\cline { 2 - 4 } & -1 & 0 & 1 \\
\hline Cutting Speed $v(\mathrm{~m} / \mathrm{min})$ & 500 & 800 & 1100 \\
\hline Feed Rate $f(\mathrm{~mm} / \mathrm{rev})$ & 0.1 & 0.2 & 0.3 \\
\hline Axial Cutting Depth $a_{p}(\mathrm{~mm})$ & 2 & 4 & 6 \\
\hline
\end{tabular}

\section{RESULTS AND DISCUSSION}

According to the design matrix, the experimental values of the NW under different cutting conditions ( $v, f$, and $a_{\mathrm{p}}$ ) were obtained (as shown in Table 4).

Table 4. Experiment Results of the NW

\begin{tabular}{|c|c|c|c|c|c|c|c|}
\hline \multirow{2}{*}{ No. } & \multicolumn{3}{|c|}{ Levels } & \multicolumn{3}{c|}{ Cutting Parameters } & NW \\
\cline { 2 - 7 } & $v$ & $f$ & $a_{p}$ & $v(\mathrm{~m} / \mathrm{min})$ & $f(\mathrm{~mm} / \mathrm{rev})$ & $a_{p}(\mathrm{~mm})$ & $(\mathrm{mm})$ \\
\hline 1 & -1 & -1 & -1 & 500 & 0.1 & 2 & 0.10950 \\
\hline 2 & 1 & -1 & -1 & 1100 & 0.1 & 2 & 0.18800 \\
\hline 3 & -1 & 1 & -1 & 500 & 0.3 & 2 & 0.09628 \\
\hline 4 & 1 & 1 & -1 & 1100 & 0.3 & 2 & 0.12753 \\
\hline 5 & -1 & -1 & 1 & 500 & 0.1 & 6 & 0.13673 \\
\hline 6 & 1 & -1 & 1 & 1100 & 0.1 & 6 & 0.22840 \\
\hline 7 & -1 & 1 & 1 & 500 & 0.3 & 6 & 0.09436 \\
\hline 8 & 1 & 1 & 1 & 1100 & 0.3 & 6 & 0.15011 \\
\hline 9 & -1 & 0 & 0 & 500 & 0.2 & 4 & 0.10345 \\
\hline 10 & 1 & 0 & 0 & 1100 & 0.2 & 4 & 0.17861 \\
\hline 11 & 0 & -1 & 0 & 800 & 0.1 & 4 & 0.15861 \\
\hline 12 & 0 & 1 & 0 & 800 & 0.3 & 4 & 0.10656 \\
\hline 13 & 0 & 0 & -1 & 800 & 0.2 & 2 & 0.12166 \\
\hline 14 & 0 & 0 & 1 & 800 & 0.2 & 6 & 0.14367 \\
\hline 15 & 0 & 0 & 0 & 800 & 0.2 & 4 & 0.13217 \\
\hline 16 & 0 & 0 & 0 & 800 & 0.2 & 4 & 0.11069 \\
\hline 17 & 0 & 0 & 0 & 800 & 0.2 & 4 & 0.11783 \\
\hline 18 & 0 & 0 & 0 & 800 & 0.2 & 4 & 0.12765 \\
\hline 19 & 0 & 0 & 0 & 800 & 0.2 & 4 & 0.14127 \\
\hline 20 & 0 & 0 & 0 & 800 & 0.2 & 4 & 0.12048 \\
\hline
\end{tabular}

\section{Mathematical Regression Model and Verification}

Mathematical regression model of tool wear

For the RSM, the response function used to represent tool wear can be expressed as Eq. 1,

$$
N W=F\left\{v, f, a_{\mathrm{p}}\right\}
$$

where NW $(\mathrm{mm})$ is the response value, $F$ is the response function, $v(\mathrm{~m} / \mathrm{min})$ is the cutting speed, $f(\mathrm{~mm} / \mathrm{rev})$ is the feed rate, and $a_{\mathrm{p}}(\mathrm{mm})$ is the axial cutting depth (Prasad et al. 2010). 
The second order response surface regression equation used to represent the response surface for the NW factors is shown in Eq. 2,

$$
Y=A_{0}+\sum_{i=1}^{n} A_{i} X_{i}+\sum_{i, j=1}^{n} A_{i j} X_{i} X_{j}+\sum_{i=1}^{n} A_{i i} X_{i}^{2}
$$

where $Y$ is the response value, $A_{0}$ is the free term of the equation, the terms with coefficients $A_{1}, A_{2}, \ldots, A_{\mathrm{n}}$ are linear terms, the terms with $A_{12}, A_{13}, \ldots, A_{(\mathrm{n}-1) \mathrm{n}}$ are the interaction terms, and the terms with $A_{11}, A_{22}, \ldots, A_{\text {nn }}$ are quadratic terms.

For three factors, the selected second order response surface regression equation of tool wear can be expressed as Eq. 3,

$$
\begin{aligned}
& N W=A_{0}+A_{1} v+A_{2} f+A_{3} a_{p}+A_{12} v f+A_{13} v a_{p}+A_{23} f a_{p}+ \\
& A_{11} v^{2} A_{22} f^{2}+A_{33} a_{p}^{2}
\end{aligned}
$$

where the variables were the same as Eq. 2.

The values of the coefficients in Eq. 3 could be calculated via the regression method. According to the test data values in Table 4, the value of the coefficients in Eq. 3 were analyzed and calculated using the Design-Expert experimental design software (Version 10, Stat-Ease, Minneapolis, MN), and the mathematical model of tool wear was obtained, as shown in Eq. 4,

$$
\begin{gathered}
N W=0.12718+0.03323 v-0.02464 f+0.01103 a_{p}-0.0106 v f+ \\
0.00471 v a_{p}-0.00587 f a_{p}+0.0106 v^{2}+0.00216 f^{2}+0.00224 a_{p}^{2}
\end{gathered}
$$

where the variables were the same as Eq. 1.

\section{Model feasibility analysis}

Feasibility analysis of the established regression model was performed using the analysis of variance (ANOVA) method (Xiao et al. 2018). Table 5 shows the ANOVA table for the regression model of tool wear. The "Prob $>F$ " value of the model was less than 0.0001 (as shown in Table 5), which implied the established regression model is feasible. The $\mathrm{R}^{2}$ and adjusted $\mathrm{R}^{2}$ of the model were 0.9642 and 0.9319 , respectively, which indicated that the independent variables selected by the model fit the dependent variables very well.

Table 5. ANOVA Table of the Model

\begin{tabular}{|c|c|c|c|c|c|c|}
\hline Source & $\begin{array}{c}\text { Sum of } \\
\text { Squares }\end{array}$ & $\begin{array}{c}\text { Degree of } \\
\text { Freedom }\end{array}$ & $\begin{array}{c}\text { Mean } \\
\text { Square }\end{array}$ & F value & Prob>F & \\
\hline Model & 0.021 & 9 & $2.285 \mathrm{E}-003$ & 29.89 & $<0.0001$ & Significant \\
\hline Residual & $7.645 \mathrm{E}-004$ & 10 & $7.645 \mathrm{E}-005$ & - & - & - \\
\hline Lack of Fit & $1.648 \mathrm{E}-004$ & 5 & $3.296 \mathrm{E}-005$ & 0.27 & 0.9087 & $\begin{array}{c}\text { Not } \\
\text { Significant }\end{array}$ \\
\hline Pure Error & $5.998 \mathrm{E}-004$ & 5 & $1.200 \mathrm{E}-004$ & - & - & - \\
\hline Total & 0.021 & 19 & - & - & - & - \\
\hline & \multicolumn{7}{|c|}{$\mathrm{R}^{2}=0.9642$, adjusted $\mathrm{R}^{2}=0.9319$} & & \\
\hline
\end{tabular}

\section{Model regression coefficient significance test and optimization}

The significance of the model population does not fully explain the fact that the independent variable is important for the dependent variable, since there might be some scenarios where the independent variable does not work or should be replaced by other, more important, dependent variables (Mandal et al. 2011; Ni et al. 2019). Therefore, the significance of the established model regression coefficients was tested, and the results are 
shown in Table 6 . For the linear terms, the cutting speed $(A)$, feed rate $(B)$, and axial cutting depth $(C)$ had a significant effect on tool wear (the "Prob $>F$ " value was less than 0.01 ). For the interaction terms, the interaction between $v$ and $f(A B)$ had a significant effect on tool wear (the "Prob $>F$ " value was less than 0.01 ), while the interactions were not significant (the "Prob $>$ F" value was greater than 0.05 ). For the second order terms, all terms did not exhibit a significant influence on tool wear (the "Prob $>F$ " value was greater than 0.05 ).

Table 6. Significance Test of the Model Regression Coefficient

\begin{tabular}{|c|c|c|c|c|c|}
\hline Source & $\begin{array}{c}\text { Sum of } \\
\text { Squares }\end{array}$ & $\begin{array}{c}\text { Degree of } \\
\text { Freedom }\end{array}$ & $\begin{array}{c}\text { Mean } \\
\text { Square }\end{array}$ & F value & Prob>F \\
\hline $\begin{array}{c}A \text { - cutting } \\
\text { speed }\end{array}$ & 0.011 & 1 & 0.011 & 144.46 & $<0.0001$ \\
\hline$B$ - feed rate & $6.071 \mathrm{E}-003$ & 1 & $6.071 \mathrm{E}-003$ & 79.41 & $<0.0001$ \\
\hline$C$ - axial cutting & $1.217 \mathrm{E}-006$ & 1 & $1.217 \mathrm{E}-003$ & 15.91 & 0.0026 \\
\hline$A B$ & $8.647 \mathrm{E}-004$ & 1 & $8.647 \mathrm{E}-004$ & 11.31 & 0.0072 \\
\hline$A C$ & $1.774 \mathrm{E}-004$ & 1 & $1.774 \mathrm{E}-004$ & 2.32 & 0.1587 \\
\hline$B C$ & $2.758 \mathrm{E}-004$ & 1 & $2.758 \mathrm{E}-004$ & 3.61 & 0.0867 \\
\hline$A^{2}$ & $3.091 \mathrm{E}-004$ & 1 & $3.091 \mathrm{E}-004$ & 4.04 & 0.0721 \\
\hline$B^{2}$ & $1.279 \mathrm{E}-005$ & 1 & $1.279 \mathrm{E}-005$ & 0.17 & 0.6911 \\
\hline$C^{2}$ & $1.376 \mathrm{E}-005$ & 1 & $1.376 \mathrm{E}-005$ & 0.18 & 0.6804 \\
\hline
\end{tabular}

In order to obtain the best model, the stepwise regression analysis method (alpha $=$ 0.05) was combined to eliminate the insignificant terms in the model. The optimized mathematical model of tool wear was shown in Eq. 5,

$$
\begin{aligned}
& N W=0.12806+0.03323 v-0.02464 f+0.01103 a_{p}-0.0104 v f+ \\
& 0.01324 v^{2}
\end{aligned}
$$

where the variables were the same as Eq. 1. Table 7 shows the ANOVA for the optimized model after removing the insignificant terms. It can be seen from Table 7 that the significance and fitting degree of the optimized model were still good (adjusted $\mathrm{R}^{2}=$ $0.9198)$, and all terms $\left(v, f, a_{\mathrm{p}}, v f\right.$, and $\left.v^{2}\right)$ had a strong significant effect on tool wear (the "Prob $>$ F" value was less than 0.01$)$.

\begin{tabular}{|c|c|c|c|c|c|c|}
\hline Source & $\begin{array}{l}\text { Sum of } \\
\text { Squares }\end{array}$ & $\begin{array}{l}\text { Degree of } \\
\text { Freedom }\end{array}$ & $\begin{array}{c}\text { Mean } \\
\text { Square }\end{array}$ & F value & Prob $>F$ & \\
\hline Model & 0.020 & 5 & $4.015 \mathrm{E}-003$ & 44.60 & $<0.0001$ & Significant \\
\hline $\begin{array}{c}\text { A - cutting } \\
\text { speed }\end{array}$ & 0.011 & 1 & 0.011 & 122.70 & $<0.0001$ & - \\
\hline B - feed rate & $6.071 \mathrm{E}-003$ & 1 & $6.071 \mathrm{E}-003$ & 67.45 & $<0.0001$ & - \\
\hline $\begin{array}{l}\text { C - axial } \\
\text { cutting }\end{array}$ & 1.217E-003 & 1 & 1.217E-003 & 13.52 & 0.0025 & - \\
\hline$A B$ & 8.647E-004 & 1 & 8.647E-004 & 9.61 & 0.0078 & - \\
\hline$A^{2}$ & 8.762E-004 & 1 & $8.762 \mathrm{E}-004$ & 9.73 & 0.0075 & - \\
\hline Residual & $1.260 \mathrm{E}-003$ & 14 & $9.001 \mathrm{E}-005$ & - & - & - \\
\hline Lack of fit & 6.604E-004 & 9 & 7.338E-005 & 0.61 & 0.7543 & $\begin{array}{c}\text { Not } \\
\text { Significant }\end{array}$ \\
\hline Pure Error & $5.998 \mathrm{E}-004$ & 5 & $1.200 \mathrm{E}-004$ & - & - & - \\
\hline \multirow[t]{2}{*}{ Total } & 0.021 & 19 & - & - & - & - \\
\hline & \multicolumn{4}{|c|}{$R^{2}=0.9409$, adjusted $R^{2}=0.9198$} & & \\
\hline
\end{tabular}

Table 7. ANOVA Table of the Optimized Model 
In order to determine whether the test data was normally distributed, the normal plot of the residuals was drawn (as shown in Fig. 2). Figure 2 shows that the residual distribution was close to the best fit line, so it conforms to the normal distribution. In addition, the predicted value and the actual value almost coincided with each other (as shown in Fig. 3), which further confirms the feasibility of the model.

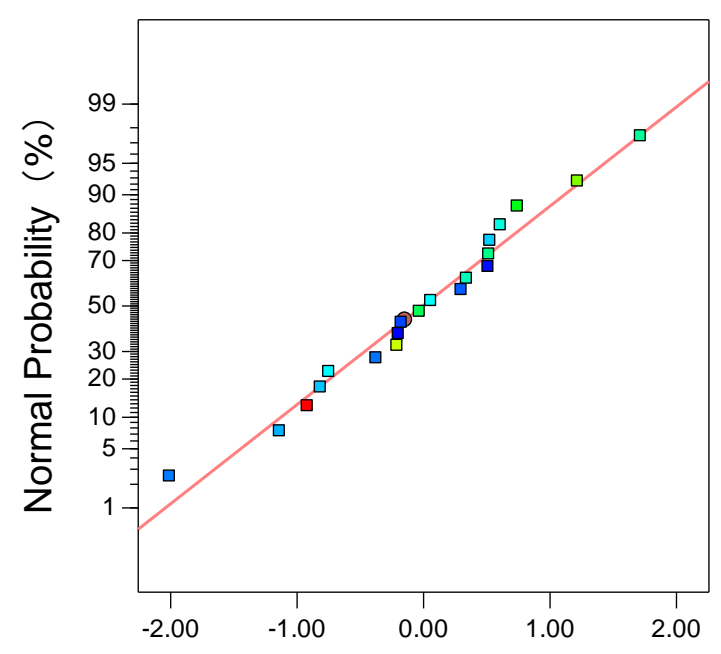

Residuals

Fig. 2. Normal plot of residuals

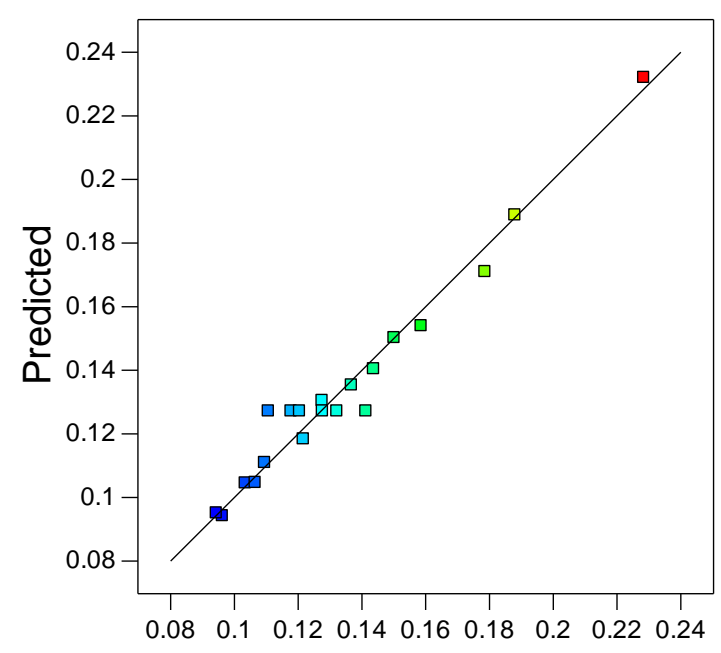

Actual

Fig. 3. Predicted vs Actual

\section{Direct Effects of Variables}

When studying tool wear, the $v$ is one of the most important factors affecting tool wear (Szwajka and Trzepiecińsk 2016). Based on the test data obtained above, the influence of $v$ on tool wear was studied for a range of $500 \mathrm{~m} / \mathrm{min}$ to $1100 \mathrm{~m} / \mathrm{min}$. As shown in Table 7, it was found that $v$ was statistically significant (the "Prob $>F$ " value was less than 0.0001$)$, and the positive coefficient $(+0.03323)$ indicated that $v$ had a positive influence on the amount of tool wear, which meant that the greater the $v$ value, the larger 
the amount of tool wear. Figure 4 shows the effect of $v$ on tool wear when $f$ and $a_{\mathrm{p}}$ are at a medium level $\left(f=0.2 \mathrm{~mm} / \mathrm{rev}\right.$ and $\left.a_{\mathrm{p}}=4 \mathrm{~mm}\right)$. It is evident from Fig. 4 that the NW increased as $v$ increased. When $v$ was increased from $500 \mathrm{~m} / \mathrm{min}$ to $1100 \mathrm{~m} / \mathrm{min}$, the $\mathrm{NW}$ increased from $0.10345 \mathrm{~mm}$ to $0.17861 \mathrm{~mm}$, or a $72.65 \%$ increase. The reason for this was that when $v$ increases, the contact frequency between the tool and workpiece increases, as well as the friction frequency, which leads to a temperature increase in the cutting edge area, the tool material softening, and the tool wearing more easily.

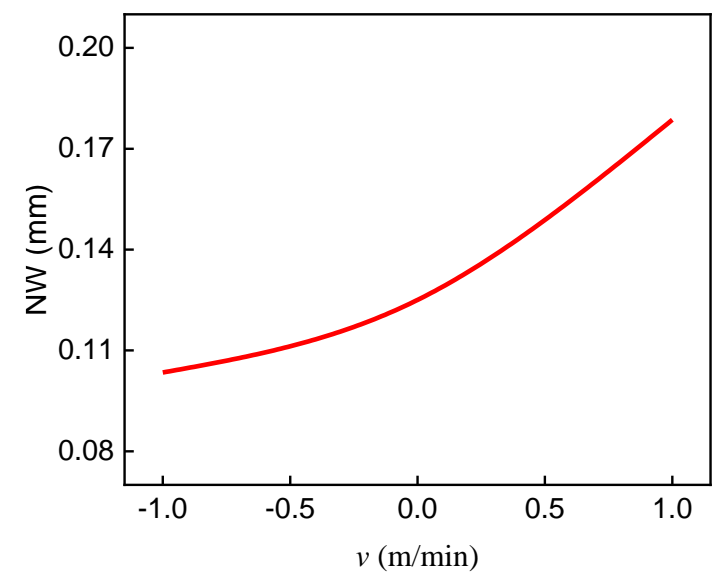

Fig. 4. The effect of the $v$ on the NW

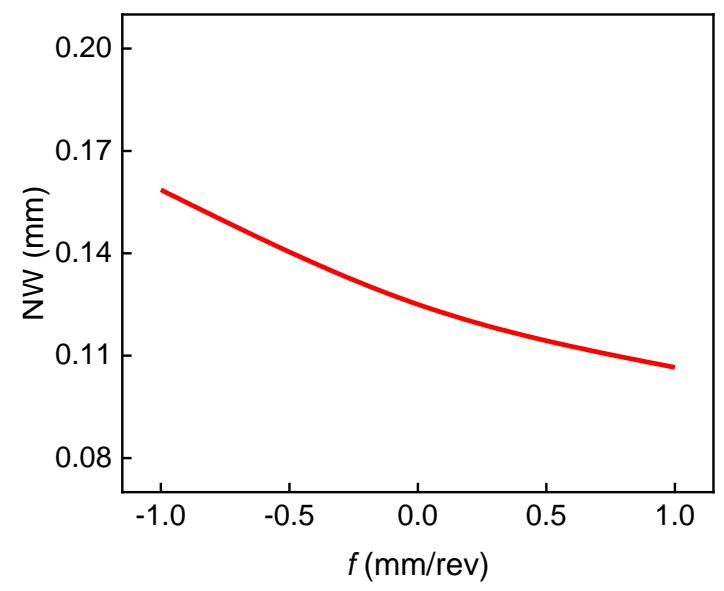

Fig. 5. The effect of the $f$ on the NW

The feed rate $(f)$ is another important parameter affecting the tool wear. When $f$ ranges from $0.1 \mathrm{~mm} / \mathrm{rev}$ to $0.3 \mathrm{~mm} / \mathrm{rev}$, it was found that $f$ had a statistical significance (the "Prob $>F$ " value was less than 0.0001), and a negative coefficient (- 0.02464) indicated that $f$ had a negative influence on the tool wear, which meant that the greater the $f$ value, the less the amount of tool wear (Table 7). Figure 5 shows the effect of $f$ on tool wear when $v$ and $a_{\mathrm{p}}$ are at a medium level $\left(v=800 \mathrm{~m} / \mathrm{min}\right.$ and $\left.a_{\mathrm{p}}=4 \mathrm{~mm}\right)$. As can be seen in Fig. 5, as the $f$ increases the NW decreases, and when the $f$ increases from $0.1 \mathrm{~mm} / \mathrm{rev}$ to 0.3 $\mathrm{mm} / \mathrm{rev}$, the NW decreases from $0.15861 \mathrm{~mm}$ to $0.10656 \mathrm{~mm}$, with a reduction rate of $32.82 \%$. According to the analysis, when milling a workpiece of the same length, the larger the $f$, the shorter contact time between the tool and workpiece, and the lower the amount of tool wear. 
In addition, when the $a_{\mathrm{p}}$ varies within $2 \mathrm{~mm}$ to $6 \mathrm{~mm}$, it was found in that $a_{\mathrm{p}}$ had statistical significance (the "Prob $>F$ " value was equal to 0.0026 , which is less than 0.05 ), and the positive coefficient $(+0.01103)$ indicated that the $a_{\mathrm{p}}$ had a positive impact on tool wear, which meant that the greater the $a_{\mathrm{p}}$ value, the greater the amount of tool wear (as shown in Table 7). Figure 6 shows the effect of $a_{\mathrm{p}}$ on the NW when $v$ and $f$ were maintained at a medium level $(v=800 \mathrm{~m} / \mathrm{min}$ and $f=0.2 \mathrm{~mm} / \mathrm{rev})$, in which the NW increases as the $a_{\mathrm{p}}$ increases. When the $a_{\mathrm{p}}$ was increased from $2 \mathrm{~mm}$ to $4 \mathrm{~mm}$, the $\mathrm{NW}$ increased from $0.12166 \mathrm{~mm}$ to $0.14367 \mathrm{~mm}$, or a $18.09 \%$ increase. This could be due to the increase in the machining capacity per unit time caused by an increase in $a_{\mathrm{p}}$, therefore applying a greater cutting force and acting force on the cutting edge of the tool (Wei et al. 2019), which speeds up the tool wear rate.

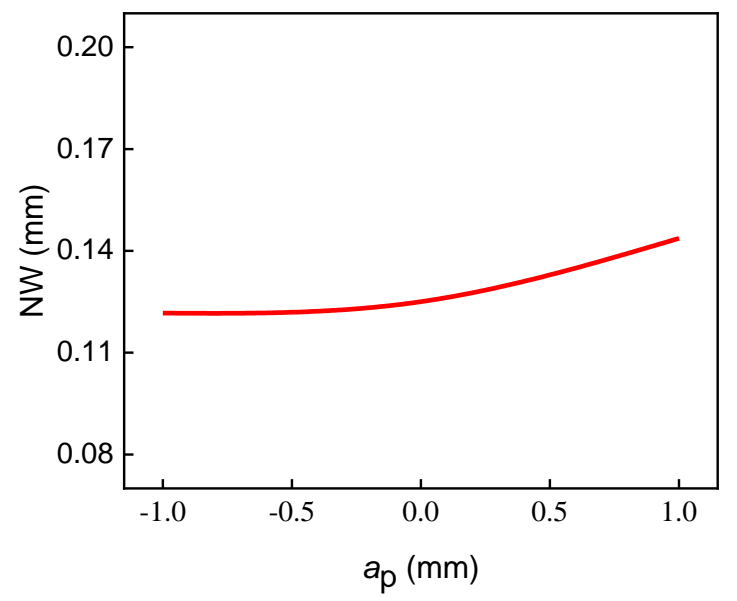

Fig. 6. The effect of the $a_{p}$ on the NW

\section{Interaction Effects of the Variables}

In order to better study the variation of tool wear in terms of the cutting parameters, 3D surface graphs and contour plots were drawn, and the interaction effect of the cutting parameters on the NW were described (Fig. 7). As can be seen in Fig. 7, the effect of the $v$ on the NW was the most significant, followed by the $f$, while the $a_{\mathrm{p}}$ had the least effect on the NW.

Figures 7a and 7b show the interaction effect of the $v$ and the $f$ on the NW at a constant $a_{\mathrm{p}}\left(a_{\mathrm{p}}=4 \mathrm{~mm}\right)$. Compared with a low $v$, it was evident (Fig. 7), that at a high $v$, the $f$ had a more obvious effect on the NW. The NW had its lowest value $(0.09436 \mathrm{~mm})$ at a cutting speed of $500 \mathrm{~m} / \mathrm{min}$ and a feed rate of $0.3 \mathrm{~mm} / \mathrm{rev}$. When the $v$ was $1100 \mathrm{~m} / \mathrm{min}$ and the $f$ was $0.1 \mathrm{~mm} / \mathrm{rev}$, the NW reached its maximum value $(0.2284 \mathrm{~mm})$.

Figures $7 \mathrm{c}$ and $7 \mathrm{~d}$ show the effect of the interaction between the $v$ and $a_{\mathrm{p}}$ on the NW when the $f$ was maintained a medium level $(f=0.2 \mathrm{~mm} / \mathrm{rev})$. When the $v$ was low, the overall change in the NW was small as the $a_{\mathrm{p}}$ increased. When the $v$ was large, the NW clearly increased as the $a_{\mathrm{p}}$ increased.

Figures 7e and $7 \mathrm{f}$ show the interaction effect of the $f$ and the $a_{\mathrm{p}}$ on the NW when $v$ was maintained a medium level ( $v=800 \mathrm{~mm} / \mathrm{min})$. It is obvious from the figure that the $a_{\mathrm{p}}$ had a small effect on the NW when machining with a high $f$.

Therefore, for a high-speed cutting process, a low $f$ and small $a_{\mathrm{p}}$ should be selected to ensure a relatively long tool life. For a low-speed cutting process, a large $f$ and $a_{\mathrm{p}}$ should be adopted to ensure a relatively long tool life while improving machining efficiency. 


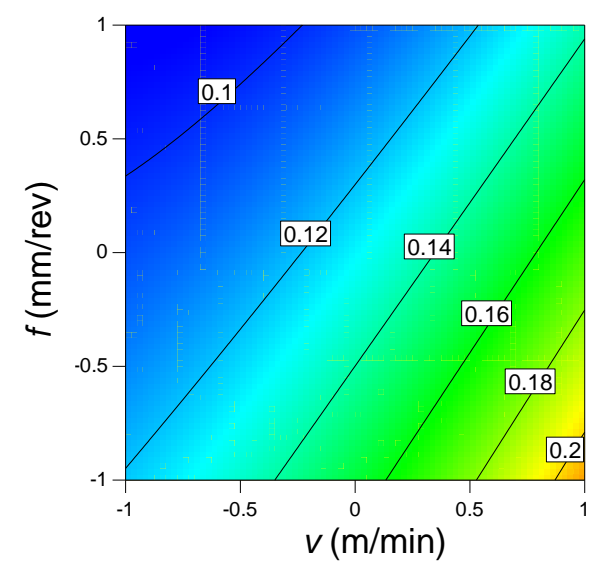

(a)

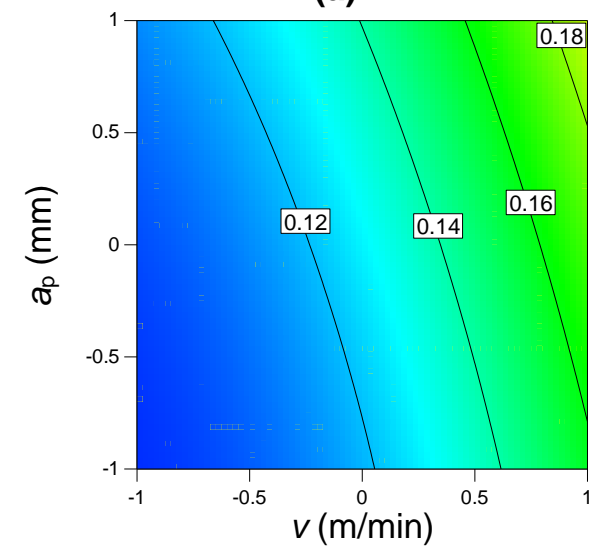

(c)

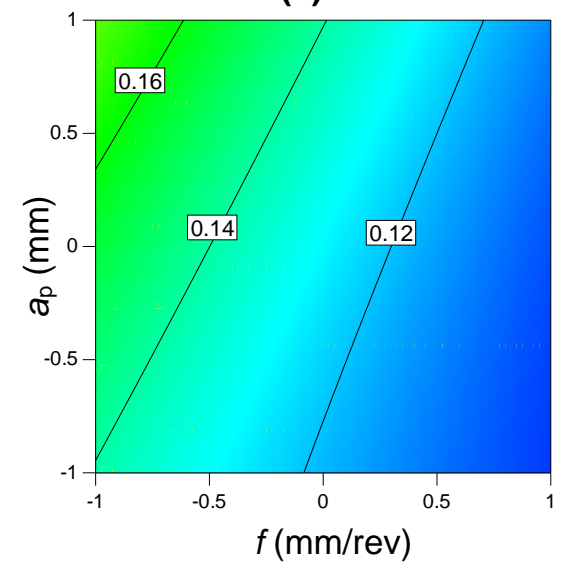

(e)

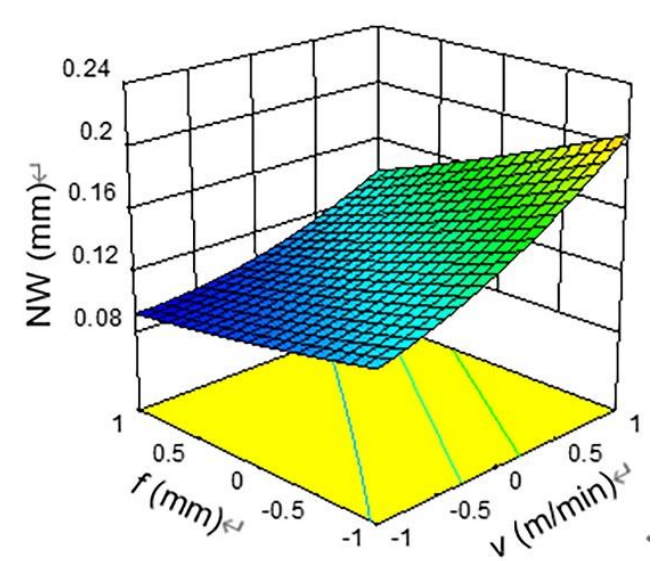

(b)

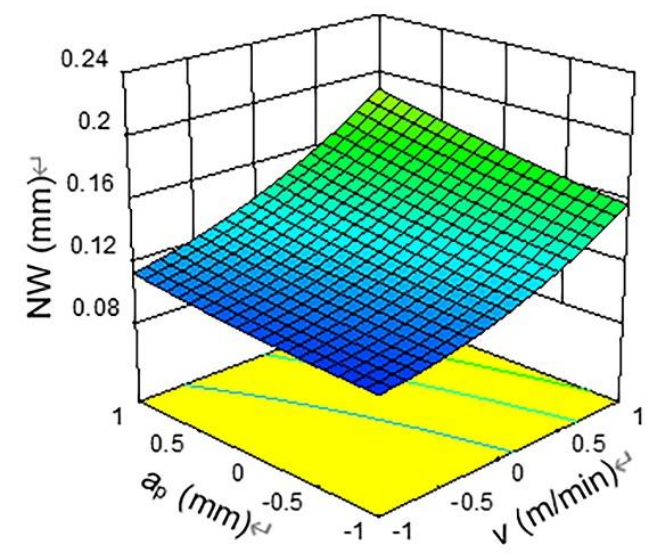

(d)

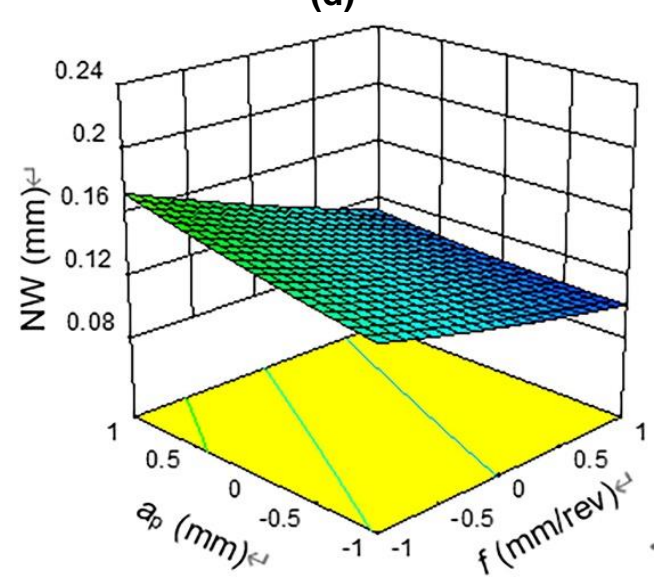

(f)

Fig. 7. The interaction effect of cutting parameters on NW 


\section{CONCLUSIONS}

1. The tool wear test showed that among the tested cutting parameters that affected the nose width $(\mathrm{NW})$, the cutting speed $(v)$ had the greatest influence, the feed speed $(f)$ had the second greatest, and the axial cutting depth $\left(a_{\mathrm{p}}\right)$ had the least. The interaction results showed that when the $v$ was high, the influence of the $f$ and the $a_{\mathrm{p}}$ on the NW was obvious, while when the $v$ was low, the $f$ and the $a_{\mathrm{p}}$ had little effect on the NW. For a high-speed cutting process, a low $f$ and small $a_{\mathrm{p}}$ should be selected to ensure the tool life. For a low-speed cutting process, a large $f$ and $a_{\mathrm{p}}$ should be adopted to ensure the tool life while improving machining efficiency.

2. The mathematical model of tool wear during the high-speed milling of WPCs was established via RSM and combined with a stepwise regression analysis to eliminate the insignificant terms in the model (as shown in Eq. 5). The ANOVA indicated that the established model was feasible, and that all terms in the model played a significant role in predicting tool wear (the "Prob $>F$ " value was less than 0.01 ).

\section{ACKNOWLEDGMENTS}

This research was financially supported by the Jiangsu Key Laboratory of Precision and Micro-Manufacturing Technology (2019), the Jiangsu "Six Talent Peak" Project (JXQC-022), and the Jiangsu University Students' Practice Innovative Training Project (202010298054Z).

\section{REFERENCES CITED}

Altan, E., Uysal, A., and Çaliskan, O. (2018). "Investigation into the effectiveness of cutting parameters on wear regions of the flank wear curve and associated cutting tool life improvement," International Journal of Materials and Product Technology 57(13), 54-70. DOI: 10.1504/IJMPT.2018.092931

Chan, K. S., Greaves, S. J., and Rahardja, S. (2019). "Techniques for addressing saddle points in the response surface methodology (RSM)," IEEE ACCESS 7, 85613-85621. DOI: 10.1109/ACCESS.2019.2922975

Darmawan, W., Tanaka, C., Usuki, H., and Ohtani, T. (2001). "Performance of coated carbide tools when grooving wood-based materials: Effect of work materials and coating materials on the wear resistance of coated carbide tools," Journal of Wood Science 47(2), 94-101. DOI: 10.1007/BF00780556

Guo, X., Zhu, Z., Ekevad, M., Bao, X., and Cao, P. (2018). “The cutting performance of $\mathrm{Al}_{2} \mathrm{O}_{3}$ and $\mathrm{Si}_{3} \mathrm{~N}_{4}$ ceramic cutting tools in the milling plywood," Advances in Applied Ceramics 117(1), 16-22. DOI: 10.1080/17436753.2017.1368946

Khuri, A. I., and Mukhopadhyay, S. (2010). "Response surface methodology,” Wiley Interdisciplinary Reviews: Computational Statistics 2(2), 128-149. DOI: 10.1002/wics.73

Mandal, N., Doloi, B., and Mondal, B. (2011). "Development of flank wear prediction model of zirconia toughened alumina (ZTA) cutting tool using response surface methodology," International Journal of Refractory Metals and Hard Materials 29(2), 273-280. DOI: 10.1016/j.ijrmhm.2010.12.001 
Ni, C., Wang, D., Vinson, R., Holmes, M., and Tao, Y. (2019). "Automatic inspection machine for maize kernels based on deep convolutional neural networks," Biosystem Engineering 178, 131-144. DOI: 10.1016/j.biosystemseng.2018.11.010

Prasad, K. S., Rao, C. S., and Rao, D. N. (2012). "Application of design of experiments to plasma arc welding process: A review," Journal of the Brazilian Society of Mechanical Sciences and Engineering 34(1), 75-81. DOI: 10.1590/S167858782012000100010

Szwajka, K., and Trzepieciński, T. (2016). "Effect of tool material on tool wear and delamination during machining of particleboard," Journal of Wood Science 62(4), 305-315. DOI: 10.1007/s10086-016-1555-6

Übeyli, M., Acir, A., Karakas, M. S., and Ögel, B. (2008). "Effect of feed rate on tool wear in milling of $\mathrm{Al}-4 \% \mathrm{Cu} / \mathrm{B}_{4} \mathrm{C}_{p}$ composite," Materials and Manufacturing Processes 23(8), 865-870. DOI: 10.1080/10426910802385059

Wang, Y. W., Li, J. F., Li, Z. M., Ding, T. C., and Zhang, S. (2011). "Experimental investigation on tool wear when end-milling inconel 718 with coated carbide inserts," Advanced Materials Research 188, 410-415. DOI: 10.4028/www.scientific.net/AMR.188.410

Wei, W., Li, Y., Xue, T., Li, Y., Sun, P., Yang, B., Yin, Z., and Mei, C. (2019a). “Tool wear during high-speed milling of wood-plastic composite," BioResources 14(1), 8678-8688. DOI: 10.15376/biores.14.4.8678-8688

Wei, W., Li, Y., Xue, T., Liu, X., Chen, L., Wang, J., Wang, T., and Cai, Y. (2019b). "Research on milling forces during high-speed milling of wood-plastic composites," BioResources 14(1), 769-779. DOI: 10.15376/biores.14.1.769-779

Wei, W., Li, Y., Xue, T., Tao, S., Mei, C., Zhou, W., Wang, J., and Wang, T. (2018). "The research progress of machining mechanisms in milling wood-based materials," BioResources 13(1), 2139-2149. DOI: 10.15376/biores.13.1.Wei

Xiao, M., Shen, X., Ma, Y., Yang, F., Gao, N., Wei, W., and Wu, D. (2018). "Prediction of surface roughness and optimization of cutting parameters of stainless steel turning based on RSM," Mathematical Problems in Engineering 2018, 1-16. DOI: $10.1155 / 2018 / 9051084$

Yi, J., Jiao, L., Wang, X., Xiang, J., Yuan, M., and Gao, S. (2015). "Surface roughness models and their experimental validation in micro milling of 6061-T6 Al alloy by response surface methodology," Mathematical Problems in Engineering 2015, 1-10. DOI: $10.1155 / 2015 / 702186$

Zhu, Z., Guo, X., Ekevad, M., Cao, P., Na, B., and Zhu, N. (2017). "The effects of cutting parameters and tool geometry on cutting forces and tool wear in milling highdensity fiberboard with ceramic cutting tools," The International Journal of Advanced Manufacturing Technology 91(9-12), 4033-4041. DOI: 10.1007/s00170017-0085-8

Article submitted: September 21, 2020; Peer review completed: October 31, 2020; Revised version received and accepted: November 2, 2020; Published: November 11, 2020.

DOI: 10.15376/biores.16.1.151-162 